\title{
The inventory-routing problem of returnable transport items with time windows and simultaneous pickup and delivery in closed-loop supply chains
}

\author{
Galina IASSINOVSKAIA ${ }^{\mathrm{a}}$, Sabine LIMBOURG $^{\mathrm{b}, *}$, Fouad RIANE $^{\mathrm{c}}$ \\ ${ }^{a}$ Louvain School of Management, Université Catholique de Louvain, Mons, Belgium \\ ${ }^{b}$ QuantOM, HEC Management School, University of Liege (ULg), Belgium \\ ${ }^{c}$ Mechanical Engineering, Industrial Management and Innovation Laboratory, Hassan Premier University, \\ Ecole Centrale Casablanca, Morocco
}

\begin{abstract}
Reducing environmental impact, related regulations and potential for operational benefits are the main reasons why companies share their returnable transport items (RTIs) among the different partners of a closed-loop supply chain. In this paper, we consider a producer, located at a depot, who has to distribute his products packed in RTIs to a set of customers. Customers define a time window wherein the service can begin. The producer is also in charge of the collection of empty RTIs for reuse in the next production cycle. Each partner has a storage area composed of both empty and loaded RTI stock, as characterized by initial levels and maximum storage capacity. As deliveries and returns are performed by a homogeneous fleet of vehicles that can carry simultaneously empty and loaded RTIs, this research addresses a pickup and delivery inventory-routing problem within time windows (PDIRPTW) over a planning horizon. A mixed-integer linear program is developed and tested on small-scale instances. To handle more realistic large-scale problems, a cluster first-route second matheuristic is proposed.

Keywords: Returnable transport item, Closed-loop supply chain, Inventory routing problem, pickups and deliveries, time windows.
\end{abstract}

\section{Introduction}

Following the first United Nations Conference on the Human Environment in 1972 and other summits on the subject, the paradigm of corporate environmental responsibility has

\footnotetext{
${ }^{*}$ Corresponding author

Email addresses: galina.iassinovskaia@uclouvain-mons.be (Galina IASSINOVSKAIA), sabine.limbourg@ulg.ac.be (Sabine LIMBOURG), fouad.riane@centrale-casablanca.ma (Fouad RIANE)
} 
taken on increasing importance among managers' top concerns. Companies are constantly looking for new innovative solutions to green their supply chains (Sarkis, 2006). However, from the perspective of Guide and Van Wassenhove (2009), environmental improvements cannot be a business goal by themselves; rather, improvements of this nature make sense with additional economical value. It has therefore been emphasized that companies experience increasing difficulties in differentiating from one another through traditional quality and cost factors. Sustainable development thus represents an alternative to improve performance in one or both aspects (New Zealand Business Council for Sustainable Development, 2003).

Increased concerns about the environmental impact of industrial activities and the search for economic advantages have given birth to the concept of a closed-loop supply chain (CLSC). As described by Akçalı and Çetinkaya (2011), a closed-loop supply chain (Corbett and Van Wassenhove, 1993; Guide et al., 1999; Gungor and Gupta, 1999; Guide, 2000; Guide and Van Wassenhove, 2003) consists of both traditional forward activities and additional return flow processes. A forward supply chain includes all activities from the extraction of raw materials to the distribution of the finished product to end customers. Return flow processes include (1) product acquisition from end-users; (2) reverse logistics to bring these back; (3) testing, sorting and disposition to determine the most economically attractive reuse option(s); (4) remanufacturing; and (5) remarketing to create and exploit new markets Guide et al., 2003).

There are various areas of research and opportunities in the CLSC field. In this context, researchers started gaining interest in regard to packaging activities. According to the Sustainable Packaging Coalition (2011), one of the criteria necessary in achieving sustainable packaging is the effective recovery of packaging at the end of their useful life, followed by subsequent reuse in industrial or biological cycles. To do so, end-of-life recovery systems must be designed to create closed-loop material chains. One of the means developed to achieve this goal makes use of returnable transport items (RTI). Alternate expressions used to label shared assets include Reusable Transport Items (IC-RTI, 2003), Returnable/Reusable Logistical Packaging (Rosenau et al., 1996) or Reusable Transport Packaging (Kärkkäinen et al., 2004). For consistency, the term returnable transport items (RTIs) will be used in reference to all such denominations throughout this paper.

RTIs consist of all means to assemble goods for transportation, storage, handling and 
product protection in a supply chain that returns goods for further usage (IC-RTI, 2003). Examples include pallets as well as all forms of reusable crates, trays, boxes, roll pallets, barrels, trolleys and pallet collars. As such, RTIs are packaging material as defined by the European Parliament and Council (2005). While RTIs are often involved in secondary and tertiary packaging, it is worth noticing that some of them might also be used as primary packaging, as underlined by the IC-RTI (2003). This is the case for the fruit juice glass bottles as long as they are not collected for recycling purpose (to turn glass-bottles into cullet).

RTIs have only arisen in the literature since the mid-1990s. The introduction of RTIs might first be explained by a growing public awareness of the impact of industrial activities on the environment. Nevertheless, the real environmental benefits provided by such assets raise doubts when considering production, management of return flows and disposal of RTIs. Indeed, to prove their efficiency, RTIs should have a less harmful impact on the environment than traditional transport items. Lammers et al. (1993) (cited by (Kroon and Vrijens, 1995)) published a comparison of the ecological impacts of one-way and returnable transport items. Based on four criteria (i.e., energy consumption, emission to the atmosphere, water consumption and pollution and solid waste), this report concludes that introducing RTIs allows for the achievement of environmental benefits. However, this finding only holds true if RTIs are used to a certain extent, i.e., a minimal number of times.

A second explanation for the increasing utilization of RTIs lies in set of regulations. Regulations are especially extensive in European countries (Kärkkäinen et al., 2004). The European directive about packaging and packaging waste (European Parliament and Council, 2005) outlines how companies should aim at minimizing their packaging production. The prevention of waste production remains the best way to address packaging management, even if reutilization, recycling and recovery are promoted as well. Moreover, producers are responsible for the entire life cycle of their packaging. The implementation of RTIs might be an answer to these issues.

Nevertheless operational benefits remain a key driver when assessing the opportunities offered by RTIs. Kärkkäinen et al. (2004) argued that an RTI program decreases the need for packaging material, enables more efficient handling, improves the working environment, enables better optimization of shipping loads and provides better protection for packaged products. 
Reducing environmental impact, related regulations and potential for operational benefits are thus the main reasons why companies have developed provisions for sharing RTIs among the different organizations in a supply chain. However, the management of RTIs is an essential component in the performance of the entire supply chain. Indeed, a breakdown in the supply of RTIs would impact the overall flow of manufactured products; for instance, such a breakdown would lead to increased delivery times to customers, induced backlogging and storage costs. Moreover, many difficulties arise when attempting to introduce or efficiently manage an RTI program. The first complication comes from the fact that, in most cases, RTI programs involve an important quantity of mobile items, which may be spatially scattered. Secondly, these important RTI stocks might be managed by several actors, each of them being responsible for a different part of the process. Finally, the effective monitoring of movements among organizations in a supply chain and the control of RTI stock levels can turn out to be particularly complicated.

In this paper, we consider the case of a two stage supply chain composed of a main producer and multiple customers. The producer manufactures and distributes its products to customers using RTIs. Since some customers are only available a short period of time to receive the products, they may define a time window during which the service can begin. The producer takes charge of the collection of empty RTIs for reuse. Each partner (i.e. producer or customers) has two main storage areas one dedicated to empty RTIs while the other serves for loaded RTIs storage. Each of these stocks is characterized by both initial levels and maximum storage capacity. This problem belongs to the family of vendor-managed inventory systems: a supplier develops a distribution strategy that minimizes the inventory holding costs and saves on distribution costs by being able to better coordinate pickups and deliveries to various customers. As deliveries and returns are performed by a homogeneous fleet of vehicles that can carry simultaneously empty and loaded RTIs, we must solve a pickup and delivery inventory-routing problem within time windows (PDIRPTW) over a planning horizon.

The main goal of this paper is to propose a mixed integer linear program for the specific case of an inventory-routing problem (IRP). The validity of this model is tested on smallscale instances. The IRP is known to be NP-hard. To solve problems of a more realistic scale, a clustering algorithm is used to reduce the original problem scale before the execution of the branch-and-cut algorithm. This clustering algorithm gathers customers' considering 
factors (e.g., demand pattern and location) that could affect operating costs throughout the planning horizon. The number of clusters corresponds to the vehicle fleet size. Afterward, the PDIRPTW is solved for each vehicle. As our approach is based on a mixed integer linear program, it can be handled by a standard optimization library. We rely here on IBM ILOG CPLEX 12.5 with the default parameters.

\section{State of the art}

As explained by Toth and Vigo (2001), the vehicle routing problem (VRP) concerns the distribution of goods between depots and customers. Its goal is to find a set of routes for a fleet of vehicles wherein the objective function (e.g., total distance and routing costs) is optimized. In our problem, each customer requires a delivery and a pickup. It is assumed that each customer can only be visited exactly once. In the literature this problem class has been first referred to as VRP with simultaneous delivery and pickup points by Min (1989), the Traveling Salesman Problem (TSP) with Pickup and Delivery by Gendreau et al. (1999), multivehicle case as VRP with simultaneous pickup and delivery by Angelelli and Mansini (2002), simultaneous VRP with Pickup and Delivery by Nagy and Salhi (2005) and Simultaneous Distribution and Collection by Dell'Amico et al. (2006). As proposed in Parragh et al. (2008), we will denote this problem class with Simultaneous Delivery and Pickup as VRPSPD.

Table 2 summarizes recent articles related to PDP published since the past 5 years. All the problems dealing with a vehicle fleet; TSP with Pickup and Delivery such as Li et al. (2011), Ting and Liao (2013) or Gendreau et al. (2015) are not included. The first column shows the references. According to the classification proposed by Berbeglia et al. (2007), three problem structures (in the Struct. column) are defined: (1) one-to-one (1-1) problems: each request originates at one location and is destined for one other location; (2) one-to-many-to-one (1M-1) problems: each customer receives a delivery originating at a common depot and sends a pickup quantity to the depot (widely used to deal with the issues in reverse logistics), and (3) many-to-many (M-M) : a commodity may be picked up at one of many locations, and also delivered to one of many locations. The third column (TW) is related to the time window. Then, the PDP variants and the solution methods are provided.

Increasing importance of reverse logistics activities (Karlaftis et al. (2009); Guide and Van Wassenhove (2009) and Souza (2013) ) lead to VRPSPD since new products and returns 


\begin{tabular}{|c|c|c|c|c|}
\hline References & Struct. & TW & Variants & Solution \\
\hline Baldacci et al. (2011) & $1-1$ & Yes & PDPTW & Exact algorithm \\
\hline Pang et al. (2011) & $1-1$ & No & SRP & $\begin{array}{l}\text { Heuristic using } \\
\text { set partitioning and column generation }\end{array}$ \\
\hline Psaraft is $(2011)$ & $1-1$ & No & VRPPD-G & Dynamic programming algorithm \\
\hline Venkateshan and Mathur (2011) & $1-1$ & No & & Column-generation \\
\hline Şahin et al. (2013) & $1-1$ & No & MPDPSL & $\begin{array}{l}\text { Heuristic combining Tabu Search } \\
\text { and Simulated Annealing }\end{array}$ \\
\hline Masson et al. (2014) & $1-1$ & Yes & & Branch-and-cut-and-price \\
\hline Benavent et al. (2015) & $1-1$ & No & PDPLT & $\begin{array}{l}\text { Heuristic using tabu search } \\
\text { in a multi-start framework }\end{array}$ \\
\hline Qu and Bard (2013) & $1-1$ & Yes & HPDP & $\begin{array}{l}\text { Heuristic based on greedy randomized adap- } \\
\text { tive search procedures with multiple starts }\end{array}$ \\
\hline Cherkesly et al. 2015 & $1-1$ & Yes & & Population-based metaheuristic \\
\hline Cherkesly et al. (2016) & $1-1$ & Yes & PDPTWMS & Exact branch-price-and-cut algorithms \\
\hline Ghilas et al. 2016 & $1-1$ & Yes & PDPTW-SL & Adaptive Large Neighborhood Search \\
\hline Subramanian et al. (2011) & $1-\mathrm{M}-1$ & No & VRPSPD & Branch-and-cut algorithm \\
\hline Garcia-Najera (2012) & $1-\mathrm{M}-1$ & No & VRPB & Multi-objective Evolutionary Algorithm \\
\hline Goksal et al. (2013) & $1-\mathrm{M}-1$ & No & VRPSPD & $\begin{array}{l}\text { Heuristic based on particle swarm } \\
\text { optimization including a local search }\end{array}$ \\
\hline Wang and Chen 2013 & $1-\mathrm{M}-1$ & Yes & FDPPTW & Coevolutionary algorithm \\
\hline Andersson et al. (2011) & M-M & Yes & PDPTWSL & Exact method \\
\hline Pelikán and Fábry (2012) & M-M & No & & Heuristic \\
\hline Petersen and Ropke (2011) & M-M & No & PDPCD & $\begin{array}{l}\text { Heuristic based on parallel adaptive } \\
\text { large neighborhood search }\end{array}$ \\
\hline Sifa et al. (2011) & M-M & Yes & UPDPFV & Tabu Search \\
\hline Liu et al. (2013) & $\mathrm{M}-\mathrm{M}$ & Yes & VRPSDPTW & Genetic Algorithm and a Tabu Search \\
\hline Ríos-Mercado et al. (2013) & M-M & Yes & & GRASP-based heuristic \\
\hline Rais et al. 2014 & $\mathrm{M}-\mathrm{M}$ & Yes & PDPT & Exact method \\
\hline Chen et al. 2015 & M-M & No & PMPDP & Bee colony optimization method \\
\hline Li et al. $(2016)$ & M-M & Yes & PDPTWPR & Adaptive Large Neighborhood Search \\
\hline
\end{tabular}

Table 1: Recent articles related to PDP 
are transported in the same vehicle. For example, empty bottles are collected as full bottles are distributed; reusable containers are collected while products are distributed (Duhaime et al. (2001)); returns are collected while new products are distributed to retailers (Mihi Ramírez (2012) and Zerhouni et al. (2013)). Mathematical models developed for the VRPSPD can be found in Dethloff (2001)), Montané and Galvão (2006) and Nagy and Salhi (2005) while the first exact algorithm has been developed by Dell'Amico et al. (2006). Many heuristic have been implemented for the VRPSPD. An up-to date literature review can be found in Avci and Topaloglu (2015) who develop an adaptive local search algorithm for this problem. Some studies, such as Hu et al. (2015), have also addressed incompatibility among transported goods in closed-loop logistics. In their work, Kassem and Chen (2013) study vehicle routing problems combining simultaneous pickup and delivery with time windows with applications in reverse logistic systems. Their solution methodology consisted of a heuristic method to generate highquality initial solutions; then a simulated-annealing-based search process is used to improve the initial solutions. Tarantilis et al. (2013) deal with the vehicle routing and scheduling problems where all delivery demands (shipment of products to linehaul customers) are initially located at the depot and correspondingly all pickup demands (collection of products from backhaul customers) are returned to the depot.

Emerging during the 1980s, IRPs are an extension of the VRP in which routing, delivery scheduling and inventory policy decisions have to be synchronized and taken jointly. Ghiani et al. (2004) define IRP as "deciding which customers to visit during each period (e.g., one day) of a given time horizon (e.g., one week) and how much to deliver to each one of them", whereas Bertazzi et al. (2008) explain that "the inventory component arises because customers consume products over time and have a limited storage capacity. It adds a time dimension to the traditional special dimension of routing problems". This time dimension increases the complexity of routing decisions. Indeed, when determining the quantity to be delivered to a customer, truck and storage capacity have to be taken into consideration. Furthermore, IRPs have to address longer planning horizons, compared with VRP which are usually busy within a single day. In addition, decisions made on a single day can easily affect future situations. Next, whereas out-of-stock items should not be experimented upon, keeping items in stock has a cost that impacts the objective function. The latter is to find the inventory policy that minimizes total cost, in other words, that minimizes the sum of inventory holding and 
transportation costs while simultaneously allowing no stock out and satisfying storage and vehicle capacities. Therefore, it is logical to observe that the delivery frequency tends to be higher when holding is high.

IRP arises when vendor-managed inventory routing (VMI) is being used; that is, when decisions about deliveries (i.e., timing, sizing and routes) are determined by the supplier and not by the customer, as a result of mutual agreement. As such, there are no customer orders. A supplier develops a distribution strategy that minimizes inventory holding costs and saves on distribution costs as he or she can coordinate pickups and deliveries to various customers. Buyers also benefit by not allocating efforts to inventory control. Traditionally, VMI has been in practice in gas and petrochemical industry distribution, though it is now becoming more common in retail businesses such as Walmart.

Coelho et al. (2013) present a comprehensive literature review of the IRP, including its main variants, models and algorithms. The authors focus on the methodological aspects of the problem, whereas a survey conducted by Andersson et al. (2010) highlights industrial applications. Kim et al. (2014) develop an analytical model of a closed-loop supply chain for deteriorating products under stochastic container return times. The authors also present the results of a simulation study. To the authors' knowledge, in maritime transportation, pickups and deliveries problems within an IRP context have been studied since the paper of Christiansen and Nygreen (1998). For these maritime IRPs, we refer to the survey paper by Christiansen et al. (2013) and to GeorgiaTech (2016) for the more recent papers. Regarding PDP, only one paper in Table 1 is related to an 1-M-1 with TW but, comparatively to our paper, Wang and Chen (2013) do not consider inventory costs. The problem described in Van Anholt et al. (2013) is the closest to our work. The authors model and solve the problem arising in the replenishment of automated teller machines. Even if there are points in common, there are also some differences due to characteristics of commodities. For instance, in their paper, commodities can be brought from and to the depot, as we do, but they can also being exchanged among customers; there is only one kind of commodities instead of two (loaded and empty RTIs); moreover, time windows are not considered. 


\section{Problem description}

One of the main sources of difficulties when managing an RTI program comes from the involvement of many different actors:

- An RTI Supplier produces RTIs and sells them to the RTI Pool Owner.

- RTI Pool Owner(s) manage(s) the whole (and/or part of the) RTI pool and make(s) RTIs available for additional supply chain levels.

- A supplier uses RTIs to distribute its goods. Suppliers fill empty RTIs they receive from an RTI Pool Owner and hand them over filled to Producers.

- Producers receive filled RTIs from Suppliers, using these or other RTIs to distribute their own production. They make non-used RTIs available for collection.

- Retailers receive filled RTIs, making them available for collection. When final customers use the RTI, i.e., when RTIs are used as primary packaging, they have the same role as Retailers.

- Logistics service providers (LSP) collect RTIs from Producers/Retailers to RTI Pool Owners, offering additional services such as cleaning or repair.

Figure 1 1llustrates the generic organization among these actors. Nevertheless, it is worth noting that depending on the strategic decisions made, one actor may take charge over several functions. For example, a single company may be both RTI Pool Owner and Supplier.

When involved in RTI management, companies have to make several decisions. RTIusing companies must decide for which purposes and how they will use returnable assets. These two questions lead them to several basic management choices, mainly regarding the configuration and size of the RTI pool, as well as storage and collection modalities. In addition to the management of their own RTI-related operations, companies must also coordinate with their partners' operations. Moreover, the RTI Pool Owner is generally in charge of both the collection of empty RTIs and the redistribution of these items after the potential required maintenance operations. Finally, RTI-using companies have to assess the costs and benefits when implementing an RTI program. Rosenau et al. (1996) provide a comprehensive list of cost factors that must be considered when RTIs are adopted, including packaging material 


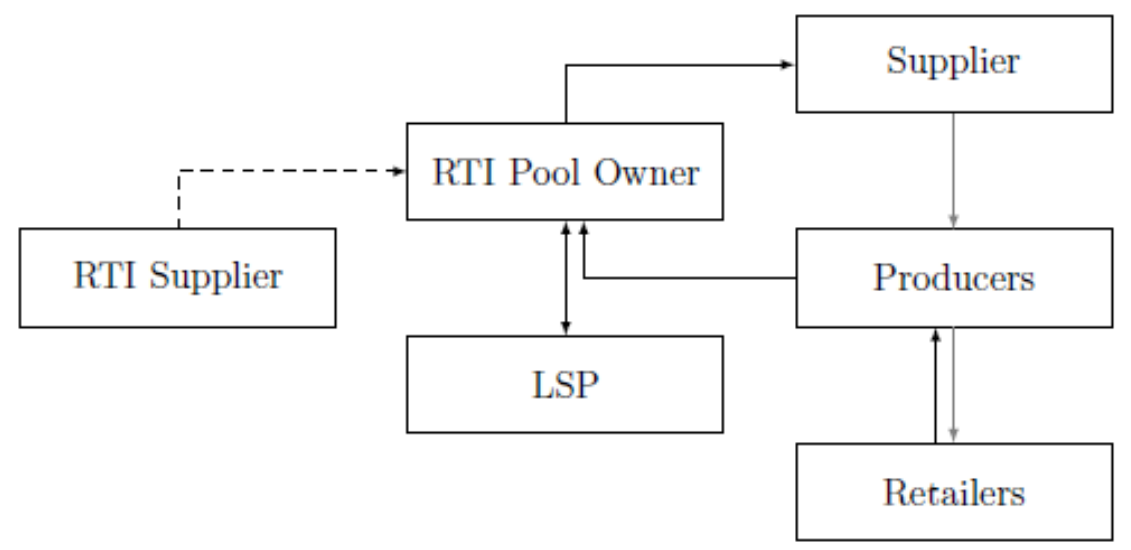

-- New RTI $\longrightarrow$ Empty RTI $\longrightarrow$ Full RTI $\longleftrightarrow$ Bilateral contracts

Figure 1: Generic view of RTI flows in a supply chain (LogicaCMG, 2004)

cost, damage reduction, inbound transportation, outbound transportation, sorting, solid waste reduction, cubic efficiency, tracking, labour, maintenance and line layout changes, in addition to ergonomics and safety. Mason et al. (2012) highlight that, in addition to all of these relevant issues, the notion of shrinkage (i.e., theft, misplacement or damage of RTIs) is key in the context of gas cylinders because many cylinders cost more to replace than the value of the gas contained within them.

The present paper addresses a specific organization of RTIs management system. It focuses on a two stage supply chain, described in Figure 2, where a producer uses RTIs to pack and distribute its products to a set of customers. RTIs are either new ones bought from RTI suppliers or reused ones collected from customers. Each partner (either the producer or a customer) devotes two storage areas: one for the empty RTI stock (E) and one for the loaded stock of RTIs (L). Each of these stocks is characterized by both initial levels and maximum storage capacity. Deliveries and returns are made by a homogeneous fleet of vehicles. A vehicle can carry simultaneously empty and loaded RTIs. Some customers require a time window. We must thus solve a pickup and delivery (1-M-1) inventory-routing problem within time windows over a planning horizon.

According to the survey conducted by Limbourg et al. (2016), the RTI cost goes from few euros for plastic boxes to $1300 €$ for stillages (used to transport flat glass for construction) 


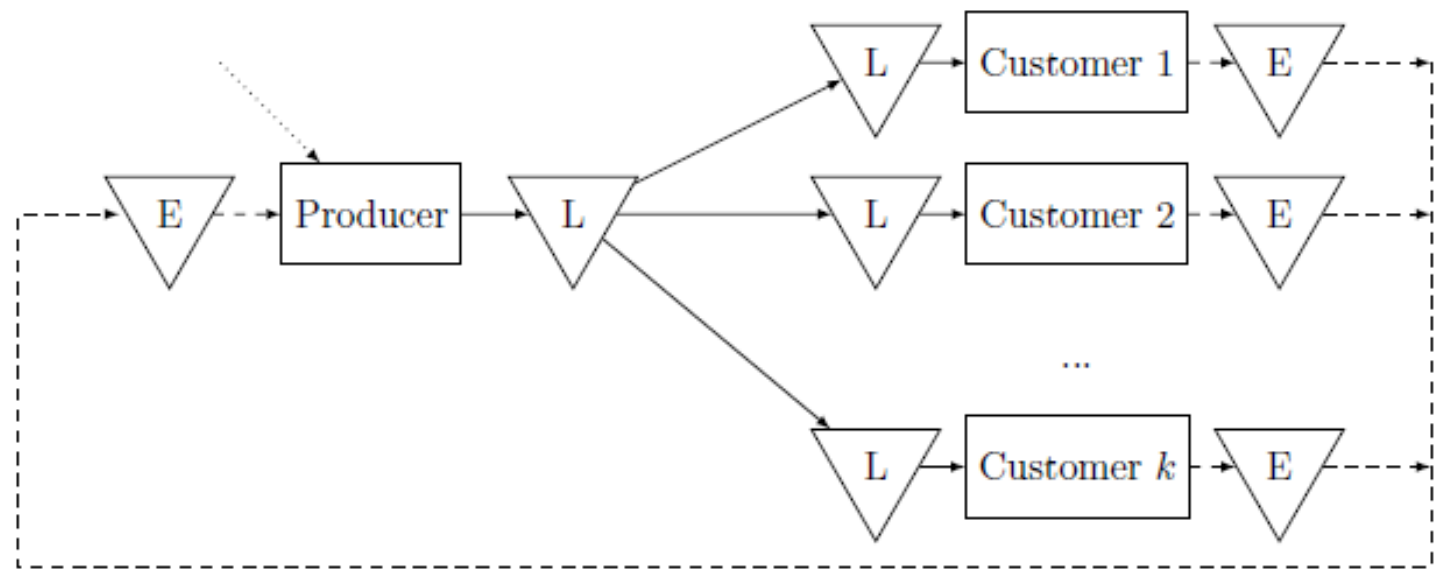

$\longrightarrow$ Loaded RTI -.. Empty RTI ....... New RTI

Figure 2: RTI flows

passing through the intermediary cost of about $10 €$ per pallet. The maintenance cost goes from $0.12 €$ for pallets to $170 €$ for stillages. However, in their study, several RTIs can be reused without any maintenance operations.

If 30-foot trucks are considered which consist of a tractor, a trailer and a container; in total, 22 pallets may be placed inside a truck in two horizontal rows (Pollaris et al. (2014)). More pallets can be loaded on these trucks when vertical stacking is allowed. The products have to be distributed in some urban areas which involve relatively low speed limits of more or less $50 \mathrm{~km} / \mathrm{h}$ and a transportation cost around $1 € / \mathrm{km}$. As the fuel consumption depends on the truck weight (see for instance Demir et al. (2011)), the cost component split separates the cost per kilometers from the costs per tonne.kilometer (express in km.item) and from the driving time.

We also have the realistic assumption that the capacity of the producer warehouse is greater than the customers' ones and, thus, allows a lower holding costs thanks to economies of scale. Moreover, as the capital tied-up is lower for empty RTIs compare to loaded RTIs, we also assume a lower holding cost for empty RTIs than for loaded RTIs. Production and consumption quantities depend on the product considered. Moreover, truck capacity and RTIs costs depend on the type of RTI used. That is why, based on the previous data, several scenarios are studied in section 6.4 


\section{Mathematical programming formulation}

The PDIRPTW problem is defined on a directed graph $G=(N, A)$ where $N$ is the set of nodes indexed by $i, j \in\{0, \ldots, n\}$ and $A=\{(i, j): i, j \in N, i \neq j\}$ is the arc set. Node 0 represents the producer location and the set $N_{0}=N \backslash\{0\}$ denotes the customer locations. Each customer $i$ has a demand $u_{i t}$ at period $t$. Moreover, each customer and the producer incur unit inventory holding costs per period $(\forall i \in N), h_{i}^{L}$ for the loaded RTI and $h_{i}^{E}$ for the empty RTI, with inventory capacities $C_{i}^{L}$ for the loaded RTI and $C_{i}^{E}$ for the empty RTI. Inventories are not allowed to exceed the holding capacity and must be positive. The length of the planning horizon is $p$ with discrete time periods $t \in T=\{1, \ldots, p\}$. A set of vehicles

$v \in V=\{1, \ldots, k\}$ are available, each with a capacity $Q$ in terms of number of RTIs without distinction between empty and loaded RTIs, with $\alpha$, a fixed cost per $\mathrm{km} ; \beta$ a variable cost per tonne.km and with an average speed $s$ in $\mathrm{km} / \mathrm{h}$. An empty RTI weighs $w_{E}$, and a loaded RTI weighs $w_{L}$. Each vehicle is able to perform a route per period, from the producer to a subset of customers. At the customer's gate, a fixed time in hours, $g$ is incurred. A distance $d_{i i}$ is associated for all $(i, j) \in A$. The service of a customer $i \in N_{0}$ can begin within a time window $\left[e_{i}, l_{i}\right]$. The vehicle cannot arrive earlier than time $e_{i}$ and no later than time $l_{i}$. The producer is assumed to have sufficient inventory and capacity to perform all of the pickups and deliveries during the planning horizon. The cost to buy a new RTI is $b$; the production cost per RTI is $c$, including inspection and cleaning costs incurred at the producer and is proportional to the number of RTIs used at the producer. At the beginning of the planning horizon, the producer knows current inventory levels: $I_{i 0}^{L}$ of the loaded RTI and $I_{i 0}^{E}$ of the empty RTI, and receives information on the demand of each customer $i$ for each period $t$. The objective of the problem is to minimize the total cost while satisfying the inventory level constraints for each customer in each period. It is assumed that every customer can only be visited exactly once in each time period. Moreover, a penalty cost per unit of time, $\varepsilon$ is added for the time length of the route.

Decision variables used in the formulation are a set of binary variables $y_{i j v t}$ equal to 1 if and only if $\operatorname{arc}(i, j)$ is used on the route of vehicle $v$ in period $t$; the integer variables are listed as follows: 
$I_{i t}^{L} \quad$ inventory level of loaded RTI at node $i$ at the end of period $t$;

$I_{i t}^{E} \quad$ inventory level of empty RTI at node $i$ at the end of period $t$;

$q_{i t} \quad$ loaded RTI quantity delivered to node $i$ in period $t$;

$r_{i t} \quad$ empty RTI returned from node $i$ in period $t$;

$x_{i j t}$ loaded RTI quantity transported from node $i$ to node $j$ in period $t$;

$z_{i j t}$ empty RTI quantity transported from node $i$ to node $j$ in period $t$;

$p_{t} \quad$ RTI quantity filled from the producer in period $t$;

$n_{t} \quad$ new RTI quantity bought and filled from the producer in period $t$;

and the real variables are:

$m_{\text {ivt }}$ the arriving time of vehicle $v$ to customer $i$ in period $t$;

$\delta_{v t} \quad$ the time length of the route.

The inventory routing problem with Simultaneous Pickup and Delivery in a closed-loop (PDIRPTW) is then formulated as follows:

$$
\begin{aligned}
\min \sum_{i \in N} \sum_{j \in N} \sum_{t \in T}\left(\alpha \sum_{v \in V} y_{i j v t}\right. & \left.+\beta\left(w_{L} x_{i j t}+w_{E} z_{i j t}\right)\right) d_{i j} \\
& +\sum_{i \in N} \sum_{t \in T}\left(h_{i}^{L} I_{i t}^{L}+h_{i}^{E} I_{i t}^{E}\right)+\sum_{t \in T} c p_{t}+\sum_{t \in T} b n_{t}+\sum_{v \in V} \sum_{t \in T} \varepsilon \delta_{v t}
\end{aligned}
$$

subject to:

$$
\begin{aligned}
x_{i j t}+z_{i j t} \leq Q \sum_{v \in V} y_{i j v t} & \forall(i, j) \in A, \forall t \in T \\
I_{i t}^{L}=I_{i t-1}^{L}+q_{i t}-u_{i t} & \forall i \in N_{0}, \forall t \in T \\
I_{i t}^{E}=I_{i t-1}^{E}-r_{i t}+u_{i t} & \forall i \in N_{0}, \forall t \in T \\
I_{0 t}^{L}=I_{0 t-1}^{L}+p_{t}-\sum_{i \in N} q_{i t} & \forall t \in T \\
I_{0 t}^{E}=I_{0 t-1}^{E}-p_{t}+n_{t}+\sum_{i \in N} r_{i t} & \forall t \in T \\
0 \leq I_{i t}^{L} \leq C_{i}^{L} & \forall i \in N, \forall t \in T \\
0 \leq I_{i t}^{E} \leq C_{i}^{E} & \forall i \in N, \forall t \in T \\
p_{t} \leq I_{0 t-1}^{E}+n_{t} & \forall t \in T \\
\sum_{i \in N, i \neq j}\left(x_{i j t}-x_{j i t}\right)=q_{j t} & \forall j \in N_{0}, \forall t \in T
\end{aligned}
$$




$$
\begin{aligned}
& \sum_{i \in N, i \neq j}\left(z_{j i t}-z_{i j t}\right)=r_{j t} \quad \forall j \in N_{0}, \forall t \in T \\
& \sum_{i \in N, i \neq j} y_{i j v t}-\sum_{i \in N, i \neq j} y_{j i v t}=0 \quad \forall j \in N, \forall v \in V, \forall t \in T \\
& \sum_{i \in N} \sum_{v \in V} y_{i j v t} \leq 1 \quad \forall j \in N_{0}, \forall t \in T \\
& \sum_{j \in N_{0}} y_{0 j v t} \leq 1 \quad \forall v \in V, \forall t \in T \\
& r_{i t} \leq I_{i t}^{E} \quad \forall i \in N_{0}, \forall t \in T \\
& q_{i t} \leq I_{i t-1}^{L} \quad \forall i \in N_{0}, \forall t \in T \\
& \sum_{i \in N} r_{i t} \leq I_{0 t}^{E} \quad \forall t \in T \\
& \sum_{i \in N} q_{i t} \leq I_{0 t-1}^{L} \quad \forall t \in T \\
& e_{i} \sum_{j \in N, j \neq i} y_{i j v t} \leq m_{i v t} \leq l_{i} \sum_{j \in N, j \neq i} y_{i j v t} \quad \forall i \in N, \forall v \in V, \forall t \in T \\
& m_{i v t}+y_{i j v t}\left(g+\frac{d_{i j}}{s}\right)-\max _{i \in N} l_{i}\left(1-y_{i j v t}\right) \leq m_{j v t} \quad \forall i \in N, j \in N_{0}, i \neq j \\
& \forall v \in V, \forall t \in T \\
& 0 \leq \delta_{v t} \leq \max _{i \in N} l_{i} \quad \forall v \in V, \forall t \in T \\
& m_{i v t}+y_{i 0 v t}\left(g+\frac{d_{i 0}}{s}\right)-\max _{i \in N} l_{i}\left(1-y_{i 0 v t}\right) \leq \delta_{v t} \quad \forall i \in N, \forall v \in V, \forall t \in T \\
& \sum_{i \in N} \sum_{v \in V} \sum_{t^{\prime}=t_{1}}^{t_{2}} y_{i j v t^{\prime}} \geq\left\lceil\frac{\sum_{t^{\prime}=t_{1}}^{t_{2}}\left(u_{j t^{\prime}}-C_{j}^{L}\right)}{\min \left\{C_{j}^{L}, Q\right\}}\right\rceil \quad \forall j \in N_{0}, \forall t_{1}, t_{2} \in T, t_{2} \geq t_{1} \\
& I_{i t}^{L}, I_{i t}^{E}, q_{i t}, r_{i t}, x_{i j t}, z_{i j t}, n_{t}, p_{t} \in \mathbb{Z}^{+} \quad \forall i, j \in N, \forall t \in T \\
& y_{i j v t} \in\{0,1\} \quad \forall(i, j) \in A, \forall v \in V, \forall t \in T
\end{aligned}
$$

The objective function (1) minimizing the total cost. The first sum of the objective function corresponds to transportation costs, the second sum corresponds to the inventory costs of empty and loaded RTIs at both customer locations and the depot, the third sum is the maintenance cost, the fourth sum represents the cost to buy new RTIs, and the last term is the penalty cost due to the time length of the route. Constraints (2) state that the vehicle capacity is not exceeded. Constraints (3) state the inventory conservation condition for the loading of RTIs over successive periods: they define the inventory in period $t$ as the inventory held in period $t-1$, plus the loaded RTI quantity delivered minus the demand. In the same 
way, constraints (4) state the inventory conservation condition for empty RTIs over successive periods: they define the inventory in period $t$ as the inventory held in period $t-1$, minus the empty RTI quantity returned plus the demand. Constraints (5) ensure inventory conservation conditions for the loading of RTIs over successive periods at the depot: the inventory in period $t$ as the inventory held in period $t-1$, plus the RTI quantity filled from the producer minus the loaded RTI quantity delivered to customers. In the same way, constraints (6) ensure inventory conservation conditions for the empty RTIs over successive periods at the depot: the inventory in period $t$ as the inventory held in period $t-1$, minus the RTI quantity filled from the producer, plus the newly bought RTIs plus empty RTIs returned from customers. Constraints (7) and (8) define the bounds on the inventory of loaded (7) and empty RTIs (8) held by each customer throughout all periods. Constraints (9) guarantee that the number of RTIs filled from the producer in period $t$ do not exceed the number of empty RTIs held in the inventory in period $t-1$ plus the number of bought RTIs. Constraints 10 indicate that loaded RTI quantities are delivered and constraints (11) that the empty RTIs are returned. Constraints (12), (13), (14) and 20 ensure that the proper vehicle routes are constructed. Constraints (12) stipulate if a vehicle $v$ visits customer $j$ in period $t$, it has to leave customer $j$ in period $t$. Constraints 13 ensure that at the most, a vehicle visits a customer per period. Constraints (14) ensure that vehicles leave the producer only once per period or stay at the depot. Constraints 15$]-18$ ensure the closed-loop chain. Constraints 15 state that the quantity of empty RTIs returned is held in the inventory. Constraints (16) state that the quantity of loaded RTIs delivered was held as inventory in the previous period. Constraints (17) state that the quantity of empty RTIs returned to the producer is held in its inventory. Constraints (18) state that the quantity of loaded RTIs delivered to the producer was held in the inventory in the previous period. Constraints (19) ensure that at each customer location, the vehicle arrives within the time window. Constraints $(20)$ ensure that the arrival time at customer $j$ has a greater value than arrival time at customer $i$ in one route. Those constraints do not need to be satisfied when the vehicle $v$ does not travel from node $i$ to node $j$ in period $t$. Constraints 21 ensure that the time length of the route is less than the maximum arrival time and constraints $(22)$, combined with the objective function, guarantee that the vehicle returns to the depot directly after serving the last customer. Based on Coelho and Laporte (2014), the valid inequalities (23) are related to whether the demand of customer $j$ for period $\left[t_{1}, t_{2}\right]$ is 
greater than its inventory capacity then a visit is required. These constraints 23 have a very positive impact on solving the ten instances included in Table 5 since the running time taken to prove optimality is reduced by half on average. This result corroborates the conclusion of Coelho and Laporte (2014). Finally, constraints (24) and 25) define non-negativity and binary conditions on the variables.

Counting all the variables and constraints described above, the number of variables is $\left(\left(2 n^{2}+8 n+8\right)+\left(n^{2}+3 n+3\right) v\right) p$ among which $(n+1)^{2} v p$ are binary variables and $2 n^{2} p+8 n p+8 p$ are integer variables. And the number of constraints is $\left(\left(3 n^{2}+18 n+15\right)+\left(n^{2}+4 n+6\right) v+\right.$ $\left.n \frac{p-1}{2}\right) p$.

\section{Computational experiments}

We have tested our mathematical model on a set of small instances. The goal is to check the validity of the model and to get some insights that could help us to develop heuristics for bigger cases. All of the optimisation steps have been performed on a personal laptop computer (Windows 8, Intel Core $2.4 \mathrm{GHz}, 8 \mathrm{~GB}$ of RAM) and with CPLEX 12.5. Because we must solve a mixed integer linear program, we have used the classical branch-and-cut CPLEX solver with the default parameters.

\subsection{Instances generation}

Small instances have been randomly generated to test our mathematical model with parameters set as follows.

- a set of $n=7$ customers: $i, j \in\{0, \ldots, 7\}$;

- a planning horizon of 5 periods: $t \in T=\{1, \ldots, 5\}$; periods coincide with days, which together define a workweek from Monday to Friday. We also test a planning horizon of 4 days, i.e., $t \in T=\{1, \ldots, 4\}$;

- a set of $v=2$ vehicles: $v \in V=\{1,2\}$; each vehicle has a capacity $Q=25$ RTIs, a fixed transportation cost $\alpha=0.8 € / \mathrm{km}$, a variable cost $\beta=0.02 € /(\mathrm{km}$.item), we assume that the difference between an empty RTI weighs and a loaded RTI is not significant and each vehicle has an average speed $s=50 \mathrm{~km} / \mathrm{h}$; 
- $h_{0}^{L}=0.015 € /($ day.item $) ; h_{0}^{E}=0.01 € /($ day.item $) ; h_{i}^{L}=0.035 € /($ day.item $) ; h_{i}^{E}=$ $0.03 € /($ day.item);

- the maintenance cost is $c=0.02 € /$ item;

- the cost to buy a new RTI is $b=10 €$;

- a penalty cost: $\varepsilon=0.01 € / \mathrm{min}$;

- the time needed at the customer's gate: $g=10$ min.

For each instance, a new set of spatial coordinates of customers are randomly generated as integers in a square of 100 units, and the location of the depot is at $(0,0)$ in the centre of the square. Distances between depot and customers and between each customer are calculated as Euclidian distances. The customer's demand for each period $t$ is a random number generated between 1 and 9 . The capacities at the depot are $C_{0}^{L}=C_{0}^{E}=10 n .2 ; C_{i}^{L}=C_{i}^{E}=2 u_{i t}$ for the customers. The initial inventory levels of loaded RTIs are equal to the customers' demand for half of the customers and to the demand for the other customers doubled, whereas initial inventory levels of empty RTIs are equal to the demand. We assume that each driver can operate $420 \mathrm{~min}(7 \mathrm{~h})$ per day and that the day begins at time 0 . All customers have a time window in minutes $\left[e_{i}, l_{i}\right]=[0,420]$. But some customers may have a tight time windows, that is why, we randomly select two customers for which one of these two time windows $[0,100]$ or $[150,250]$ is assigned. All instances can be found on the following website http://orbi.ulg.ac.be/handle/2268/189993?locale=en.

\subsection{Results on small instances}

\subsubsection{With a planning horizon of four periods}

For the sake of clarity, all customers have a constant demand over time:

$$
u_{1 t}=2 ; u_{2 t}=8 ; u_{3 t}=8 ; u_{4 t}=8 ; u_{5 t}=6 ; u_{6 t}=5 ; u_{7 t}=2 \quad \forall t \in T \text {. }
$$

Customers, denoted by $\mathrm{C}$, do not require any time windows except customer 2 (C2): $[150,250]$ and customer 6 (C6): [0, 100]. The distance matrix is described Table 2.

Tours obtained for the four periods under consideration are the same as those represented in Figure 3, wherein vehicle 1 and vehicle 2 can be interchangeable; the moments when customers are served are summarized in Table 3 , 


\begin{tabular}{|c|cccccccc|}
\hline $\mathrm{km}$ & Depot & $\mathrm{C} 1$ & $\mathrm{C} 2$ & $\mathrm{C} 3$ & $\mathrm{C} 4$ & $\mathrm{C} 5$ & $\mathrm{C} 6$ & $\mathrm{C} 7$ \\
\hline Depot & 0 & 24 & 64 & 57 & 25 & 34 & 45 & 36 \\
$\mathrm{C} 1$ & 24 & 0 & 43 & 79 & 33 & 22 & 33 & 60 \\
$\mathrm{C} 2$ & 64 & 43 & 0 & 122 & 75 & 58 & 30 & 98 \\
$\mathrm{C} 3$ & 57 & 79 & 122 & 0 & 53 & 76 & 101 & 31 \\
$\mathrm{C} 4$ & 25 & 33 & 75 & 53 & 0 & 23 & 65 & 46 \\
$\mathrm{C} 5$ & 34 & 22 & 58 & 76 & 23 & 0 & 56 & 66 \\
$\mathrm{C} 6$ & 45 & 33 & 30 & 101 & 65 & 56 & 0 & 74 \\
$\mathrm{C} 7$ & 36 & 60 & 98 & 31 & 46 & 66 & 74 & 0 \\
\hline
\end{tabular}

Table 2: Distance matrix

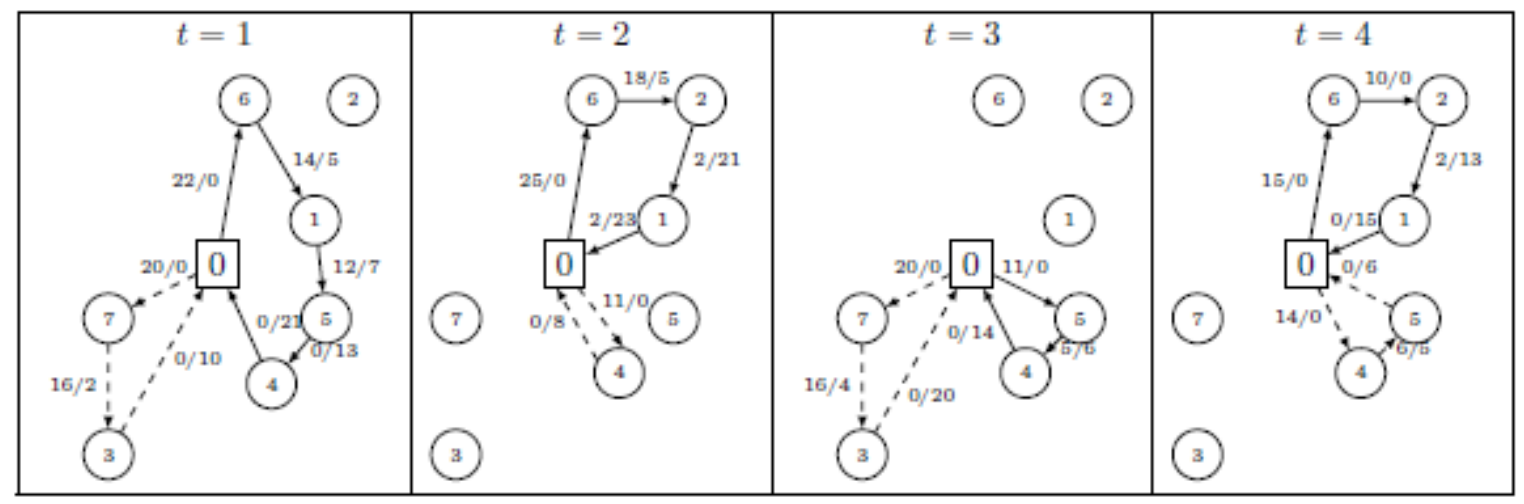

Figure 3: Loaded/Empty RTIs, the solid lines represent vehicle 1 and dashed lines the vehicle 2 


\begin{tabular}{|c|c|c|c|c|c|c|}
\hline Period & Vehicle & \multicolumn{5}{|c|}{ Moments when the customers are served (min) } \\
\hline \multirow{4}{*}{$t=1$} & \multirow{2}{*}{1} & C6 & $\mathrm{C} 1$ & $\mathrm{C} 5$ & $\mathrm{C} 4$ & Depot \\
\hline & & 64 & 113.6 & 150 & 187.6 & 227.6 \\
\hline & \multirow{2}{*}{2} & $\mathrm{C} 7$ & C3 & Depot & & \\
\hline & & 53.2 & 100.4 & 178.8 & & \\
\hline \multirow{4}{*}{$t=2$} & \multirow{2}{*}{1} & $\mathrm{C} 6$ & $\mathrm{C} 2$ & C1 & Depot & \\
\hline & & 64 & 150 & 211.6 & 250.4 & \\
\hline & \multirow{2}{*}{2} & $\mathrm{C} 4$ & Depot & & & \\
\hline & & 40 & 80 & & & \\
\hline \multirow{4}{*}{$t=3$} & \multirow{2}{*}{1} & C5 & $\mathrm{C} 4$ & Depot & & \\
\hline & & 50.8 & 88.4 & 128.4 & & \\
\hline & \multirow{2}{*}{2} & $\mathrm{C} 7$ & C3 & Depot & & \\
\hline & & 53.2 & 100.4 & 178.8 & & \\
\hline \multirow{4}{*}{$t=4$} & \multirow{2}{*}{1} & C6 & $\mathrm{C} 2$ & C1 & Depot & \\
\hline & & 64 & 150 & 211.6 & 250.4 & \\
\hline & \multirow{2}{*}{2} & $\mathrm{C} 4$ & C5 & Depot & & \\
\hline & & 40 & 77.6 & 128.4 & & \\
\hline
\end{tabular}

Table 3: Moments when the customers are served

\subsubsection{Variation among inventory capacities}

Starting from the case described in section 5.2.1, four other cases are generated when the inventory capacities for empty and loaded RTIs at the customers correspond to (I) daily demand, (II) two (case of section 5.2.1), (III) three, (IV) four and (V) fivefold demands. In Table 4 , different costs are compared. Case (I) is a VRP in which inventory capacities are equal to demands, with no extra inventories allowed. As expected, when inventory capacities increase, transportation costs are reduced and inventory costs increase up to case IV. Then, in case $\mathrm{V}$, increasing the inventory capacity at customer locations does not improve the solution because there are no more possibilities for saving inventories in this case. The production cost is constant because the demand is constant, and new RTIs have to be bought to allow for a larger stock.

\subsubsection{Additional cases}

The good results presented above encourage us to conduct extra experiments to confirm the representativeness of the results and to evaluate the time needed to solve this problem. To provide partial insights, we have solved ten cases of the same scale with different demand 


\begin{tabular}{|r|r|r|r|r|r|}
\cline { 2 - 6 } & \multicolumn{5}{|c|}{ Capacity in terms of demand } \\
\cline { 2 - 6 } & I & II & III & IV & V \\
\hline Transportation cost & 1486.000 & 1011.500 & 894.500 & 852.620 & 852.620 \\
Inventory cost & 14.295 & 17.365 & 19.095 & 20.125 & 20.125 \\
Production cost & 1.360 & 1.360 & 1.360 & 1.360 & 1.360 \\
New RTI cost & 0.000 & 80.000 & 130.000 & 130.000 & 130.000 \\
Penalty cost & 20.512 & 14.228 & 12.872 & 12.652 & 12.652 \\
\hline Total cost & $\mathbf{1 5 2 2 . 1 6 7}$ & $\mathbf{1 1 2 4 . 4 5 3}$ & $\mathbf{1 0 5 7 . 8 2 7}$ & $\mathbf{1 0 1 6 . 7 5 7}$ & $\mathbf{1 0 1 6 . 7 5 7}$ \\
\hline
\end{tabular}

Table 4: Total cost according to the inventory capacity

patterns and distance matrix for two planning horizons of four and five periods. Computational results are summarized in Table 5, where row 8 for four periods corresponds to the cases presented in section 5.2.1. Column 1 shows the number of the instances while in the next six columns, we present respectively transportation cost, inventory cost, production cost, new RTI cost, the penalty cost and the total cost; in the last column we provide the computational time. All constraints are satisfied, and we always obtain optimal solutions. Instances, even small scale ones, can be time-consuming to solve.

\section{Heuristic}

To solve problems of realistic proportions, a clustering heuristic is used before executing the branch-and-cut algorithm. Clustering is the partitioning of a dataset into subsets, or clusters, in such a way that the nodes in each subset share some common characteristics and are therefore different from those in other clusters. The aim of a clustering heuristic is to reduce the time needed by the branch-and-cut algorithm by assigning a set of customers to each vehicle. One advantage is that customers can be served by a specific driver as the number of clusters corresponds to vehicle fleet size.

\subsection{Procedure}

Our procedure is based on the multi-period clustering problem (MPC) described in Nananukul (2013) assuming that the number of clusters corresponds to vehicle fleet size.

New binary variables are defined: $\chi_{i v}=1$ if and only if customer $i$ is served by vehicle $v$ and $\varphi_{i j v}=1$ if and only if customers $i$ and $j$ are served by vehicle $v$; the MPC model is as follows: 


\begin{tabular}{|c|c|c|c|c|c|c|c|}
\hline Case & Trans. cost & Inv. cost & Prod. cost & RTI cost & Penalty cost & Total cost & Time (s) \\
\hline \multicolumn{8}{|c|}{4 periods } \\
\hline 1 & 1099.90 & 16.630 & 1.16 & 110 & 13.728 & 1241.418 & 52.52 \\
\hline 2 & 847.80 & 13.675 & 0.86 & 0 & 12.800 & 875.135 & 58.14 \\
\hline 3 & 825.16 & 16.755 & 1.38 & 40 & 13.620 & 896.915 & 261.62 \\
\hline 4 & 721.08 & 15.270 & 0.96 & 20 & 10.944 & 768.254 & 157.50 \\
\hline 5 & 1040.30 & 16.510 & 1.14 & 10 & 17.828 & 1085.778 & 782.58 \\
\hline 6 & 933.42 & 18.320 & 1.64 & 140 & 12.848 & 1106.228 & 456.44 \\
\hline 7 & 728.82 & 15.865 & 1.04 & 20 & 12.040 & 777.765 & 139.98 \\
\hline 8 & 1011.50 & 17.365 & 1.36 & 80 & 14.228 & 1124.453 & 55.89 \\
\hline 9 & 880.94 & 14.610 & 0.98 & 20 & 12.584 & 929.114 & 30.97 \\
\hline 10 & 729.54 & 14.865 & 1.22 & 10 & 12.012 & 767.637 & 327.59 \\
\hline \multicolumn{8}{|c|}{5 periods } \\
\hline 1 & 1418.40 & 20.800 & 1.88 & 110 & 18.388 & 1569.448 & 607.14 \\
\hline 2 & 1053.00 & 17.425 & 1.46 & 40 & 15.476 & 1127.361 & 127.86 \\
\hline 3 & 1064.80 & 21.210 & 2.16 & 60 & 17.484 & 1165.614 & 5251.68 \\
\hline 4 & 912.62 & 19.165 & 1.62 & 50 & 14.820 & 998.225 & 3214.45 \\
\hline 5 & 1258.20 & 20.990 & 1.88 & 90 & 20.820 & 1391.850 & 13034.84 \\
\hline 6 & 1173.80 & 20.535 & 2.26 & 140 & 17.968 & 1354.563 & 7115.91 \\
\hline 7 & 971.12 & 19.685 & 1.74 & 10 & 15.636 & 1018.181 & 2679.61 \\
\hline 8 & 1260.90 & 22.305 & 2.14 & 160 & 16.932 & 1462.257 & 1270.22 \\
\hline 9 & 1139.60 & 21.015 & 2.06 & 110 & 18.704 & 1291.399 & 684.55 \\
\hline 10 & 902.82 & 18.435 & 1.92 & 0 & 14.768 & 937.943 & 648.48 \\
\hline
\end{tabular}

Table 5: Computational time for the exact method 


$$
\min \sum_{i \in N_{0}} \sum_{j \in N_{0}} \sum_{v \in V} d_{i j} \varphi_{i j v}
$$

subject to:

$$
\begin{aligned}
\sum_{v \in V} \chi_{i v}=1 & \forall i \in N_{0} \\
\sum_{i \in N_{0}} \sum_{t^{\prime}=1}^{t} u_{i t^{\prime}} \chi_{i v} \leq t Q & \forall v \in V, t \in T \\
\varphi_{i j v} \leq \chi_{i v} & \forall i, j \in N_{0}, v \in V \\
\varphi_{i j v} \leq \chi_{j v} & \forall i, j \in N_{0}, v \in V \\
\varphi_{i j v} \geq \chi_{i v}+\chi_{j v}-1 & \forall i, j \in N_{0}, v \in V \\
\chi_{i v}, \varphi_{i j v} \in\{0,1\} & \forall i, j \in N_{0}, v \in V
\end{aligned}
$$

The objective function 26 is to minimize the sum of the distances between customers in each cluster. Constraints 27 ensure that each customer is assigned to a cluster. Constraints 28 indicate that the total demand of each customer belonging to a cluster over the planning horizon must fit into available capacity, $t Q$, for all clusters. Constraints (29)-(31) specify that the distance between customers $i$ and $j$, served by the vehicle $v$, is included in the objective function if and only if customers $i$ and $j$ are assigned to the same cluster. Finally, constraints (32) impose binary restrictions upon variables $\chi_{i v}$ and $\varphi_{i j v}$.

To speed up the clustering, the model MPCS is defined by including constraints (33) and (34) in MPC.

$$
\begin{aligned}
\sum_{v \in V} \max _{i, j \in N_{0}} d_{i j} \cdot \varphi_{i j v} \geq \gamma_{1}-d_{i j} \quad \forall i, j \in N_{0} \\
\left(d_{i j}-\gamma_{2}\right) \cdot \varphi_{i j v} \leq 0 \quad \forall i, j \in N_{0}, v \in V
\end{aligned}
$$

Constraints (33) force the closest nodes $i$ and $j \in N_{0}$ to be in the same cluster if $d_{i j} \leq \gamma_{1}$. Whereas, constraints (34) force the furthest nodes, i.e. nodes $i$ and $j \in N_{0}$ such that $d_{i j} \geq \gamma_{2}$, to be in different clusters. In the following instances, $\gamma_{1}$ is the $(0.1(1-v / n))^{t h}$ percentile and $\gamma_{2}$ is the $(1-(v-1) / n)^{t h}$ percentile of the distance matrix. 
Once the set of customers, $N_{0}$, is divided into $v$ clusters, i.e. $v$ sets of customers $N[v]$, the PDIRPTW model is solved for each cluster and for one vehicle as explained in Algorithm 1 .

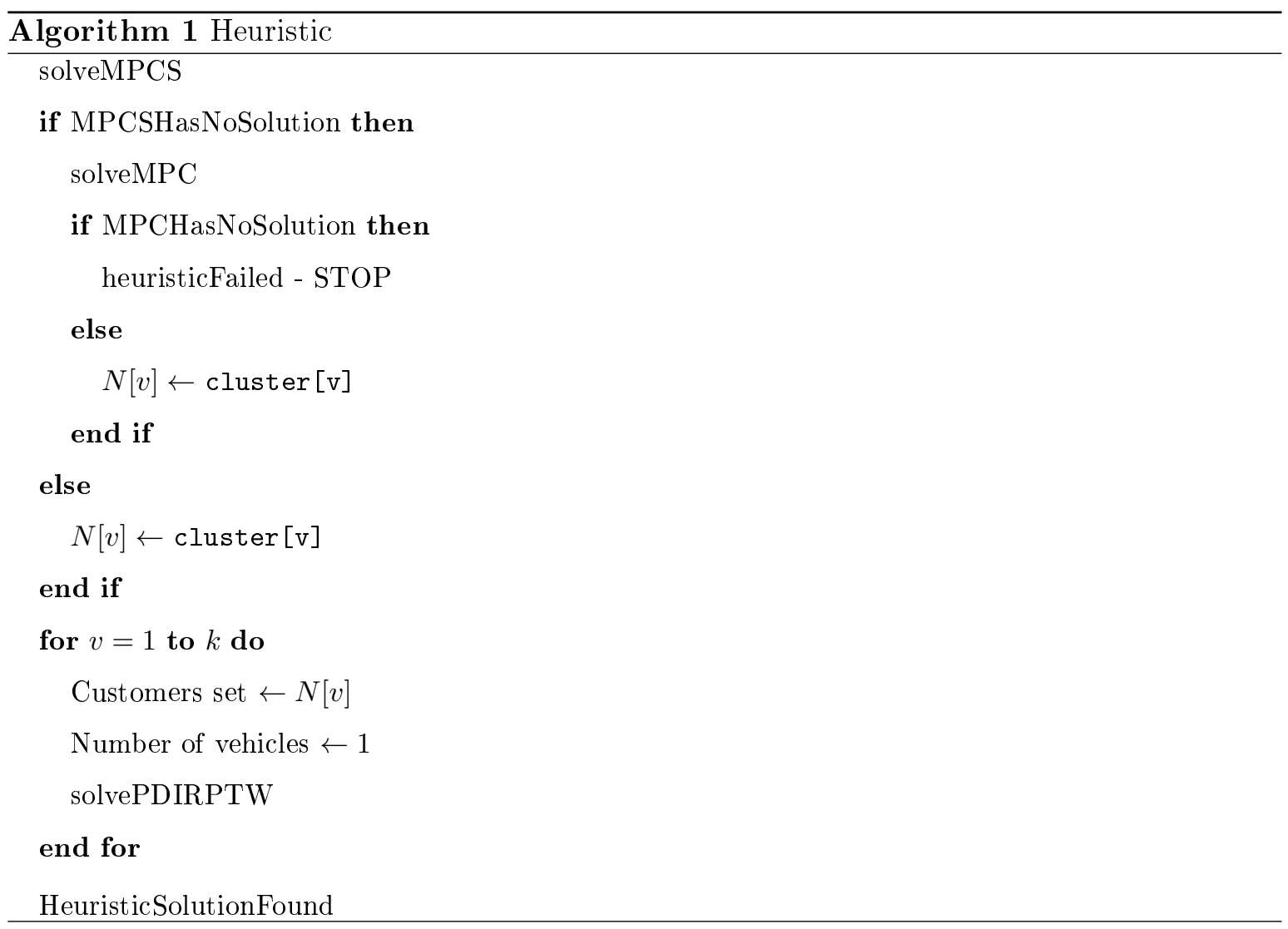

\subsection{Heuristic versus optimal method}

In general, the optimality gap is defined as a percentage or ratio measure to investigate problem solving approaches and determine how close a solution is to the optimum value. As a performance measure, we consider the relative gap between the solution returned by our heuristic $(\mathrm{H})$ and the optimal solution $(\mathrm{S})$ which is included in Table 5 for the 10 instances. For each instance, the value of the relative gap is computed as (H-S)/S and included in Table 6 . A relative gap of zero means our heuristic resulted in the optimal solution. Even if the gap is quite large for some instances, all solutions were obtained within a few seconds (columns 4 and 7). This heuristic is thus a very promising constructive heuristic.

\subsection{Results on realistic sized problems}

Table 7 summarizes the obtained solutions for 48 realistically sized problems. These larger instances are generated in the same way as presented in section 5.1. We arbitrarily set the 


\begin{tabular}{|r||r|r|r|r|r|r|}
\hline & \multicolumn{3}{|c|}{4 periods } & \multicolumn{3}{|c|}{5 periods } \\
\hline \hline Cases & $\mathrm{H}$ & Gap (\%) & Time (s) & $\mathrm{H}$ & Gap (\%) & Time (s) \\
\hline 1 & 1345.753 & 8.40 & 0.750 & 1694.381 & 7.96 & 0.766 \\
2 & 920.357 & 5.17 & 0.422 & 1194.252 & 5.93 & 0.735 \\
3 & 1024.811 & 14.26 & 0.563 & 1219.506 & 4.62 & 0.921 \\
4 & 828.895 & 7.89 & 0.829 & 1087.330 & 8.93 & 3.140 \\
5 & 1231.553 & 13.43 & 0.842 & 1514.935 & 8.84 & 5.500 \\
6 & 1280.936 & 15.79 & 0.516 & 1569.355 & 15.86 & 0.688 \\
7 & 793.478 & 2.02 & 0.517 & 1038.782 & 2.02 & 0.814 \\
8 & 1155.024 & 2.72 & 0.860 & 1483.378 & 1.44 & 1.108 \\
9 & 1062.450 & 14.35 & 0.594 & 1368.519 & 5.97 & 1.048 \\
10 & 800.302 & 4.26 & 1.610 & 975.359 & 3.99 & 1.390 \\
\hline
\end{tabular}

Table 6: Relative gap between the heuristic and the optimal solution

maximum CPU time for CPLEX and for the heuristic to be at most one hour. Blank cells indicate instances where the computation time exceeded this time limit. The first column is the name of the instances. An instance name is denoted as c[the number of customers]d[maximum value of the demand]-[number], e.g. c20d4-1 is the first instance including 20 customers with a demand for each period $t$ that corresponds to a random number generated between 1 and 4. The second column is $k$, the number of vehicles. In the next three columns, we present respectively the Best Integer $(\mathrm{BI})$, the Best Bound $(\mathrm{BB})$ and the relative CPEX Gap, that is, the relative difference between the objective value of the best feasible solution and the best known lower bound: $(B I-B B) / B I$. In the sixth column, we provide the objective value obtained by our heuristic. Column named "Clust. Time" shows the computational time needed to solve the clustering part; column named "IRPs Time" is the sum of the computational times needed to solve the PDIRPTW for each cluster and the following column is the time needed by the heuristic (i.e. sum of the two previous columns). Note that the computational time for the heuristic can easily be reduced by parallelizing the PDIRPTW for each cluster as all these PDIRPTWs are independent from each other. Finally, the last column, named $\mathrm{Gap}_{C H}$, gives the percentage gap between the best integer and the heuristcs value: $(B I-O b j) / B I$. In this column, a positive value results from a better heuristic solution. Instances can be found on the following website http://orbi.ulg.ac.be/handle/2268/189993?locale=en.

From this table, we can see that CPLEX can find a feasible solution within one hour for 
6 instances out of 48 but it cannot find any optimal solution within this time limit. However, except for one case in Table 7, the heuristic always find a feasible solution. But, as the considered clustering problem is a NP-Hard problem, the time needed to solve it becomes greater than one hour for four other tested instances including 30 customers with a demand for each period $t$ that corresponds to a random number generated between 1 and 9 . The average computational time for the solved instances is less than $360 \mathrm{~s}$ and more than $50 \%$ of the instances are solved in less than $60 \mathrm{~s}$. It is rather reasonable and dramatically smaller than for the classical branch-and-cut CPLEX solver with the default parameters.

\begin{tabular}{|c|c|c|c|c|c|c|c|c|c|}
\hline \multirow[t]{2}{*}{ Instance } & \multirow[t]{2}{*}{$k$} & \multicolumn{3}{|c|}{ CPLEX (3600 s) } & \multicolumn{4}{|c|}{ Heuristics } & \multirow{2}{*}{$\begin{array}{r}\operatorname{Gap}_{C H} \\
(\%)\end{array}$} \\
\hline & & $\begin{array}{r}\text { Best } \\
\text { integer }\end{array}$ & $\begin{array}{r}\text { Best } \\
\text { bound }\end{array}$ & $\begin{array}{r}\text { CPEX } \\
\text { Gap (\%) }\end{array}$ & Obj. & $\begin{array}{r}\text { Clust. } \\
\text { Time (s) }\end{array}$ & $\begin{array}{r}\text { IRPs } \\
\text { Time (s) }\end{array}$ & $\begin{array}{r}\text { Time } \\
(\mathrm{s})\end{array}$ & \\
\hline c $20 \mathrm{~d} 4-1$ & 4 & & 1522 & & 2429 & 0.625 & 802.464 & 803.089 & \\
\hline c20d4-1 & 5 & & 1791 & & 2502 & 0.656 & 772.929 & 773.585 & \\
\hline c $20 \mathrm{~d} 4-1$ & 6 & 2540 & 1803 & $29.01 \%$ & 2566 & 0.766 & 3.922 & 4.688 & $-1.02 \%$ \\
\hline c20d4-2 & 4 & & 1342 & & 2052 & 0.734 & 57.285 & 58.019 & \\
\hline c20d4-2 & 5 & & 1446 & & 2167 & 0.859 & 16.204 & 17.063 & \\
\hline $\mathrm{c} 20 \mathrm{~d} 4-2$ & 6 & & 1436 & & 2272 & 334.471 & 2.875 & 337.346 & \\
\hline c $20 \mathrm{~d} 4-3$ & 4 & & 1086 & & 1751 & 0.734 & 1054.606 & 1055.340 & \\
\hline c20d4-3 & 5 & & 1250 & & 1879 & 1.516 & 58.346 & 59.862 & \\
\hline c20d4-3 & 6 & & 1252 & & 1914 & 1889.700 & 2.624 & 1892.324 & \\
\hline c20d4-4 & 4 & & 1387 & & 2234 & 0.766 & 58.035 & 58.801 & \\
\hline c $20 \mathrm{~d} 4-4$ & 5 & & 1515 & & 2339 & 0.703 & 5.031 & 5.734 & \\
\hline c20d4-4 & 6 & & 1520 & & 2354 & 488.103 & 7.471 & 495.574 & \\
\hline c20d4-5 & 4 & & 1353 & & 2158 & 0.547 & 27.766 & 28.313 & \\
\hline c20d4-5 & 5 & & 1598 & & 2281 & 0.625 & 14.110 & 14.735 & \\
\hline c20d4-5 & 6 & & 1598 & & 2375 & 2.078 & 4.172 & 6.250 & \\
\hline c20d9-1 & 5 & 4107 & 2893 & $29.56 \%$ & 3646 & 0.656 & 17.735 & 18.391 & $11.22 \%$ \\
\hline c20d9-1 & 6 & & 2902 & & 3827 & 0.453 & 9.877 & 10.330 & \\
\hline c20d9-1 & 7 & & 2880 & & 3924 & 1.360 & 2.924 & 4.284 & \\
\hline c20d9-2 & 5 & 3793 & 2874 & $24.23 \%$ & 3526 & 0.688 & 22.861 & 23.549 & $7.04 \%$ \\
\hline c20d9-2 & 6 & & 2866 & & 3646 & 0.766 & 12.283 & 13.049 & \\
\hline c20d9-2 & 7 & 3733 & 2863 & $23.31 \%$ & 3814 & 0.880 & 2.546 & 3.426 & $-2.16 \%$ \\
\hline c20d9-3 & 5 & & 2294 & & 2907 & 1.531 & 73.053 & 74.584 & \\
\hline c20d9-3 & 6 & 3075 & 2281 & $25.83 \%$ & 3125 & 0.641 & 11.018 & 11.659 & $-1.62 \%$ \\
\hline c20d9-3 & 7 & 3133 & 2299 & $26.63 \%$ & 3210 & 2.000 & 2.406 & 4.406 & $-2.48 \%$ \\
\hline c $20 \mathrm{~d} 9-4$ & 5 & & 3119 & & 4105 & 0.734 & 7.452 & 8.186 & \\
\hline
\end{tabular}




\begin{tabular}{|c|c|c|c|c|c|c|}
\hline c20d9-4 & 6 & 3131 & 3800 & 53.690 & 3.673 & 57.363 \\
\hline c20d9-4 & 7 & 3136 & 4030 & 620.142 & 3.076 & 623.218 \\
\hline c20d9-5 & 5 & 2304 & 2899 & 2.484 & 5.280 & 7.764 \\
\hline c20d9-5 & 6 & 2298 & 2958 & 0.625 & 3.639 & 4.264 \\
\hline c20d9-5 & 7 & 2299 & 3102 & 1.062 & 3.060 & 4.122 \\
\hline c30d4-1 & 5 & 1720 & 2229 & 1.188 & 674.317 & 675.505 \\
\hline c30d4-1 & 6 & 1729 & 2004 & 1.594 & 383.894 & 385.488 \\
\hline c30d4-1 & 7 & 1713 & 2051 & 3.876 & 52.769 & 56.645 \\
\hline c30d4-2 & 5 & 2111 & 3005 & 1.797 & 924.031 & 925.828 \\
\hline c30d4-2 & 6 & 2110 & 3199 & 1.672 & 472.274 & 473.946 \\
\hline c30d4-2 & 7 & 2110 & 3355 & 3.094 & 34.813 & 37.907 \\
\hline c30d4-3 & 5 & 1934 & 2783 & 1.593 & 1817.418 & 1819.011 \\
\hline c30d4-3 & 6 & 1979 & 2898 & 1.938 & 1217.671 & 1219.609 \\
\hline c30d4-3 & 7 & 1887 & 2961 & 1.703 & 298.093 & 299.796 \\
\hline c30d4-4 & 5 & 1827 & 2711 & 1.422 & 1384.058 & 1385.480 \\
\hline c30d4-4 & 6 & 1816 & 2858 & 3.266 & 348.704 & 351.970 \\
\hline c30d4-4 & 7 & 1794 & 2949 & 389.942 & 242.201 & 632.143 \\
\hline c30d4-5 & 5 & 2170 & 3065 & 1.656 & 870.650 & 872.306 \\
\hline c30d4-5 & 6 & 2138 & 3172 & 2.094 & 456.914 & 459.008 \\
\hline c30d4-5 & 7 & 2128 & 3205 & 2.516 & 435.381 & 437.897 \\
\hline c30d9-1 & 6 & 3070 & & & & \\
\hline c30d9-1 & 7 & 3073 & 4183 & 2.094 & 179.761 & 181.855 \\
\hline c30d9-1 & 8 & 3056 & 4246 & 2.141 & 48.048 & 50.189 \\
\hline
\end{tabular}

Table 7: Results on realistic sized problems

\subsection{Scenario analysis}

Table 8 summarizes the obtained solutions for several scenarios. The first column is the name of the instances. The second column is $k$, the number of vehicles. In the next columns, we present respectively the objective value obtained by our heuristic (Obj.) and the number of RTIs bought $(\#)$ for the reference scenario and for scenarios in which

- the truck capacity is doubled (1);

- holding costs are 10 times higher (2);

- transport costs are 2 times higher (3);

- RTI costs are higher (4); 
- more tight TW are required by customers (5).

Increasing truck capacity from 25 to 50 RTIs allows a reduction of the total cost which is obtained by a more efficient clustering (in 9 out of 30 cases). Indeed, some customers close to each other cannot belong to the same cluster due to the capacity constraints (28). The latter are weakened as Q increases. Transportation costs are thus lowered and, in one case, fewer RTIs are needed, resulting in lower buying costs. However, in 18 cases, more RTIs are bought; this also enables to reduce the transportation cost since more products can be transported in a period while no or fewer customers are visited in the next period.

Holding costs 10 times higher lead to an increasing of the total cost (12.9\% on average) and, in 8 cases, in a decreasing of the number of RTIs bought. In one case, c20d9-5 with 6 vehicles, one more RTI is bought, reducing the transportation costs in one cluster.

Whereas a doubling in the fixed and variable transportation costs results in a significant increasing of the total cost $(87.7 \%$ on average). And, to permit to moderate the traveling distance, an increasing of the number of RTIs bought is also observed in 21 cases.

Face with the rising costs related to RTIs (the cost to buy a new RTI is set at $1300 €$ and the maintenance cost at $170 €)$, a strong decreasing of the number of RTIs bought is observed in all the examined cases.

Finally, more tight time windows are introduced: customers can have a time windows of 150 minutes: for instance: $[0,150]$ or $[270,330]$ with a probability of $1 / 20$. Some customers want to be served in the beginning of the day: $[0,210]$ with a probability of $5 / 20$; in the end of the day: $[210,420]$ with a probability of $5 / 20$; or during the day without other time restriction: $[0,420]$ with a probability of $5 / 20$. In 26 cases, the total cost increase often due to the time needed for the tours. In 12 cases, fewer RTIs are bought and in 3 cases more RTIs are bought. The average computational time is still reasonable since for the reference scenarios it is $274 s$, $173 s$ for scenarios (1), $155 s$ for scenarios (2), $113 s$ for scenarios (3), $115 s$ for scenarios (4) and $100 s$ for scenarios $(5)$.

\begin{tabular}{|r|c|c|c|c|c|c|c|c|c|c|c|c|c|}
\hline & & \multicolumn{2}{|c|}{$\begin{array}{c}\text { Reference } \\
\text { scenario }\end{array}$} & \multicolumn{2}{c|}{$\begin{array}{c}\text { Capacity } \\
\text { X } 2\end{array}$} & \multicolumn{2}{c|}{$\begin{array}{c}\text { Holding } \\
\text { costs X 10 }\end{array}$} & \multicolumn{2}{c|}{$\begin{array}{c}\text { Transport } \\
\text { costs X 2 }\end{array}$} & \multicolumn{2}{c|}{$\begin{array}{c}\text { High RTI } \\
\text { costs }\end{array}$} & \multicolumn{2}{c|}{$\begin{array}{c}\text { More } \\
\text { tight TW }\end{array}$} \\
\hline Instances & $k$ & Obj. & $\#$ & Obj. & $\#$ & Obj. & $\#$ & Obj. & $\#$ & Obj. & $\#$ & Obj. & $\#$ \\
\hline c20d4-1 & 4 & 2429 & 21 & 2392 & 26 & 2715 & 20 & 4428 & 45 & 36024 & 4 & 2523 & 19 \\
c20d4-1 & 5 & 2502 & 28 & 2500 & 28 & 2794 & 28 & 4520 & 44 & 36378 & 4 & 2519 & 31
\end{tabular}




\begin{tabular}{|c|c|c|c|c|c|c|c|c|c|c|c|c|c|}
\hline c20d4-1 & 6 & 2566 & 41 & 2566 & 41 & 2870 & 41 & 4625 & 44 & 34080 & 2 & 2597 & 41 \\
\hline c20d4-2 & 4 & 2052 & 9 & 2052 & 17 & 2284 & 9 & 3945 & 17 & 22967 & 0 & 2052 & 17 \\
\hline $\mathrm{c} 20 \mathrm{~d} 4-2$ & 5 & 2167 & 17 & 1962 & 17 & 2403 & 13 & 4106 & 17 & 22786 & 0 & 2167 & 17 \\
\hline c20d4-2 & 6 & 2272 & 18 & 2272 & 18 & 2511 & 18 & 4304 & 18 & 20855 & 0 & 2272 & 18 \\
\hline c20d4-3 & 4 & 1751 & 3 & 1706 & 8 & 1972 & 3 & 3382 & 8 & 17506 & 0 & 1834 & 4 \\
\hline c20d4-3 & 5 & 1879 & 12 & 1823 & 12 & 2104 & 7 & 3583 & 12 & 17975 & 0 & 1940 & 8 \\
\hline c20d4-3 & 6 & 1914 & 12 & 1914 & 12 & 2143 & 12 & 3652 & 12 & 17968 & 0 & 1940 & 12 \\
\hline c20d4-4 & 4 & 2234 & 16 & 2135 & 16 & 2476 & 16 & 4249 & 16 & 20382 & 0 & 2232 & 16 \\
\hline c20d4-4 & 5 & 2339 & 17 & 2267 & 17 & 2562 & 17 & 4410 & 17 & 20893 & 0 & 2324 & 17 \\
\hline c20d4-4 & 6 & 2354 & 16 & 2300 & 16 & 2596 & 16 & 4486 & 16 & 20876 & 0 & 2371 & 16 \\
\hline c20d4-5 & 4 & 2158 & 33 & 2119 & 35 & 2431 & 33 & 3916 & 35 & 27599 & 1 & 2170 & 33 \\
\hline c20d4-5 & 5 & 2281 & 36 & 2281 & 36 & 2555 & 36 & 4141 & 36 & 29434 & 2 & 2284 & 36 \\
\hline c20d4-5 & 6 & 2375 & 37 & 2375 & 37 & 2645 & 37 & 4308 & 41 & 29744 & 2 & 2379 & 37 \\
\hline c20d9-1 & 5 & 3646 & 12 & 3242 & 29 & 4178 & 12 & 6947 & 28 & 66361 & 3 & 3792 & 17 \\
\hline c20d9-1 & 6 & 3827 & 41 & 3477 & 30 & 4389 & 41 & 7084 & 62 & 78524 & 10 & 3897 & 41 \\
\hline c20d9-1 & 7 & 3924 & 41 & 3801 & 69 & 4483 & 34 & 7163 & 87 & 79826 & 13 & 3936 & 41 \\
\hline c20d9-2 & 5 & 3526 & 12 & 3359 & 42 & 4031 & 7 & 6705 & 30 & 58141 & 3 & 3602 & 15 \\
\hline c20d9-2 & 6 & 3646 & 29 & 3548 & 45 & 4172 & 24 & 6802 & 45 & 61194 & 5 & 3692 & 34 \\
\hline c20d9-2 & 7 & 3814 & 36 & 3681 & 48 & 4340 & 31 & 6999 & 53 & 61491 & 5 & 3862 & 48 \\
\hline c20d9-3 & 5 & 2907 & 2 & 2752 & 22 & 3376 & 2 & 5687 & 3 & 79303 & 0 & 3055 & 4 \\
\hline c20d9-3 & 6 & 3125 & 10 & 2931 & 22 & 3596 & 10 & 6005 & 24 & 42711 & 0 & 3253 & 12 \\
\hline c20d9-3 & 7 & 3210 & 19 & 3123 & 23 & 3699 & 19 & 6085 & 36 & 43197 & 0 & 3367 & 32 \\
\hline c20d9-4 & 5 & 4105 & 25 & 3490 & 33 & 4178 & 25 & 7769 & 39 & 79303 & 10 & 4157 & 25 \\
\hline c20d9-4 & 6 & 3800 & 45 & 3624 & 46 & 4386 & 32 & 7029 & 47 & 75503 & 7 & 3832 & 41 \\
\hline c20d9-4 & 7 & 4030 & 54 & 3899 & 67 & 4622 & 37 & 7270 & 67 & 84621 & 14 & 4066 & 54 \\
\hline c20d9-5 & 5 & 2899 & 12 & 2794 & 20 & 3393 & 12 & 5581 & 12 & 44030 & 0 & 2995 & 12 \\
\hline c20d9-5 & 6 & 2958 & 9 & 2890 & 14 & 3457 & 10 & 5725 & 10 & 44121 & 0 & 3053 & 10 \\
\hline c20d9-5 & 7 & 3102 & 16 & 3025 & 20 & 3596 & 16 & 5938 & 17 & 44545 & 0 & 3169 & 18 \\
\hline
\end{tabular}

Table 8: Scenario analysis

\section{Conclusions}

The pickup and delivery inventory-routing problem within time windows over a planning horizon is a current problem encountered in closed-loop supply chains. This paper presents a mixed-integer linear program for PDIRPTW. This formulation addresses some constraints inherent in transport such as time windows and truck capacity constraints. Another distinctive feature is the objective function, which takes into account transportation costs, inventory costs 
of empty and loaded RTIs at customer sites and at the depot, production costs, costs to buy new RTIs and penalty costs related to the time length of the route. Our contribution develops a new mathematical model taking all these specificities into account. We have tested this formulation on small-scale instances and looked at some variants of the problem. A cluster first-route second matheuristic is also developed to have a good solution for realistic instances. The obtained results would help to test the more suitable techniques and new procedures combining heuristics and exact algorithms.

\section{Acknowledgements}

We thank Célia Paquay and the anonymous referees for their valuable comments on this paper. This work was initiated as part of a research project "FEDER : MEDIATIC - TRACEMEDIA" funded by the Walloon Region and the European Union. Sabine Limbourg also

thanks the Interuniversity Attraction Poles Programme initiated by the Belgian Science Policy Office (grant P7/36). This paper, however, only expresses the authors' views.

\section{References}

Akçalı, E. and S. Çetinkaya (2011). Quantitative models for inventory and production planning in closed-loop supply chains. International Journal of Production Research 49(8), 23732407.

Andersson, H., M. Christiansen, and K. Fagerholt (2011). The maritime pickup and delivery problem with time windows and split loads. INFOR $49(2), 79-91$.

Andersson, H., A. Hoff, M. Christiansen, G. Hasle, and A. Løkketangen (2010). Industrial aspects and literature survey: Combined inventory management and routing. Computers $\mathscr{E}$ Operations Research 37(9), 1515-1536.

Angelelli, E. and R. Mansini (2002). The vehicle routing problem with time windows and simultaneous pick-up and delivery. In Quantitative approaches to distribution logistics and supply chain management, pp. 249-267. Springer.

Avci, M. and S. Topaloglu (2015). An adaptive local search algorithm for vehicle routing problem with simultaneous and mixed pickups and deliveries. Computers 69 Industrial Engineering 83, 15 - 29. 
Baldacci, R., E. Bartolini, and A. Mingozzi (2011). An exact algorithm for the pickup and delivery problem with time windows. Operations Research 59(2), $414-426$.

Benavent, E., M. Landete, E. Mota, and G. Tirado (2015). The multiple vehicle pickup and delivery problem with $\{$ LIFO $\}$ constraints. European Journal of Operational Research 243(3), $752-762$.

Berbeglia, G., J.-F. Cordeau, I. Gribkovskaia, and G. Laporte (2007). Static pickup and delivery problems: a classification scheme and survey. TOP 15(1), 1-31.

Bertazzi, L., M. Savelsbergh, and M. G. Speranza (2008). Inventory routing. In The vehicle routing problem: latest advances and new challenges, pp. 49-72. Springer.

Chen, H.-K., H.-W. Chou, C.-F. Hsueh, and Y.-J. Yu (2015). The paired many-to-many pickup and delivery problem: an application. TOP 23(1), 220-243.

Cherkesly, M., G. Desaulniers, S. Irnich, and G. Laporte (2016). Branch-price-and-cut algorithms for the pickup and delivery problem with time windows and multiple stacks. European Journal of Operational Research $250(3), 782$ - 793.

Cherkesly, M., G. Desaulniers, and G. Laporte (2015). A population-based metaheuristic for the pickup and delivery problem with time windows and $\{$ LIFO $\}$ loading. Computers Operations Research 62, 23 - 35.

Christiansen, M., K. Fagerholt, B. Nygreen, and D. Ronen (2013). Ship routing and scheduling in the new millennium. European Journal of Operational Research 228(3), 467 - 483.

Christiansen, M. and B. Nygreen (1998). A method for solving ship routing problemswith inventory constraints. Annals of Operations Research 81(0), 357-378.

Coelho, L. C., J.-F. Cordeau, and G. Laporte (2013). Thirty years of inventory routing. Transportation Science 48(1), 1-19.

Coelho, L. C. and G. Laporte (2014). Improved solutions for inventory-routing problems through valid inequalities and input ordering. International Journal of Production Economics 155, 391-397. 
Corbett, C. J. and L. N. Van Wassenhove (1993). The green fee: Internalizing and operationalizing environmental issues. California Management Review 36(1), 116-135.

Dell'Amico, M., G. Righini, and M. Salani (2006). A branch-and-price approach to the vehicle routing problem with simultaneous distribution and collection. Transportation Science $40(2), 235-247$.

Demir, E., T. Bektaş, and G. Laporte (2011). A comparative analysis of several vehicle emission models for road freight transportation. Transportation Research Part D: Transport and Environment 16(5), $347-357$.

Dethloff, J. (2001). Vehicle routing and reverse logistics: The vehicle routing problem with simultaneous delivery and pick-up. OR-Spektrum 23(1), 79-96.

Duhaime, R., D. Riopel, and A. Langevin (2001). Value analysis and optimization of reusable containers at canada post. Interfaces 31(3), 3-15.

European Parliament and Council (2005). European Parliament and Council Directive 94/62/EC of 20 December 1994 on packaging and packaging waste. Amended in 2003, 2004, 2005. http://www.tse.org.tr/docs/direktifler-form/94_62 .pdf?sfvrsn=2.

Garcia-Najera, A. (2012). Evolutionary Computation in Combinatorial Optimization: 12th European Conference, EvoCOP 2012, Málaga, Spain, April 11-13, 2012. Proceedings, Chapter The Vehicle Routing Problem with Backhauls: A Multi-objective Evolutionary Approach, pp. 255-266. Berlin, Heidelberg: Springer Berlin Heidelberg.

Gendreau, M., G. Laporte, and D. Vigo (1999). Heuristics for the traveling salesman problem with pickup and delivery. Computers \& Operations Research 26(7), 699-714.

Gendreau, M., J. Nossack, and E. Pesch (2015). Mathematical formulations for a 1-fulltruckload pickup-and-delivery problem. European Journal of Operational Research 242(3), $1008-1016$.

GeorgiaTech (2016). A library of maritime inventory routing problems. http://mirplib. scl.gatech.edu/publications Accessed: 2016-06-05.

Ghiani, G., G. Laporte, and R. Musmanno (2004). Introduction to logistics systems planning and control. John Wiley \& Sons. 
Ghilas, V., E. Demir, and T. V. Woensel (2016). An adaptive large neighborhood search heuristic for the pickup and delivery problem with time windows and scheduled lines. Computers Operations Research 72, $12-30$.

Goksal, F. P., I. Karaoglan, and F. Altiparmak (2013). A hybrid discrete particle swarm optimization for vehicle routing problem with simultaneous pickup and delivery. Computers Industrial Engineering 65(1), 39 - 53. Intelligent Manufacturing Systems.

Guide, V. D. R. (2000). Production planning and control for remanufacturing: industry practice and research needs. Journal of Operations Management 18(4), 467-483.

Guide, V. D. R., T. P. Harrison, and L. N. Van Wassenhove (2003). The challenge of closedloop supply chains. Interfaces 33(6), 3-6.

Guide, V. D. R., V. Jayaraman, and R. Srivastava (1999). Production planning and control for remanufacturing: a state-of-the-art survey. Robotics and Computer-Integrated Manufacturing $15(3), 221-230$.

Guide, V. D. R. and L. N. Van Wassenhove (2003). Business aspects of closed-loop supply chains, Volume 2. Carnegie Mellon University Press Pittsburgh, PA.

Guide, V. D. R. and L. N. Van Wassenhove (2009). The evolution of closed-loop supply chain research. Operations research 57(1), 10-18.

Gungor, A. and S. M. Gupta (1999). Issues in environmentally conscious manufacturing and product recovery: a survey. Computers 6 Industrial Engineering 36(4), 811-853.

Hu, Z.-H., J.-B. Sheu, L. Zhao, and C.-C. Lu (2015). A dynamic closed-loop vehicle routing problem with uncertainty and incompatible goods. Transportation Research Part C: Emerging Technologies 55, 273 - 297. Engineering and Applied Sciences Optimization (OPT-i) Professor Matthew G. Karlaftis Memorial Issue.

IC-RTI (2003). Reusable transport items (RTI) - organizational recommendations. http://ecr-all.org/wp-content/uploads/pub_2003_RTI_organisational_ recommendations.pdf. 
Kärkkäinen, M., T. Ala-Risku, and M. Herold (2004). Managing the rotation of reusable transport packaging-a multiple case study. In Thirteenth International Working Seminar on Production Economics, Igls, Austria.

Karlaftis, M. G., K. Kepaptsoglou, and E. Sambracos (2009). Containership routing with time deadlines and simultaneous deliveries and pick-ups. Transportation Research Part E: Logistics and Transportation Review 45(1), 210-221.

Kassem, S. and M. Chen (2013). Solving reverse logistics vehicle routing problems with time windows. The International Journal of Advanced Manufacturing Technology 68(1-4), 57-68.

Kim, T., C. H. Glock, and Y. Kwon (2014). A closed-loop supply chain for deteriorating products under stochastic container return times. Omega $43,30-40$.

Kroon, L. and G. Vrijens (1995). Returnable containers: an example of reverse logistics. International Journal of Physical Distribution $\mathcal{E}$ Logistics Management 25(2), 56-68.

Lammers, W., V. Lange, and D. Luzyna (1993). Ökologischer vergleich eines einweg- und mehrweg- transport- verpackungssystems: Endbericht. Dortmund: Frauenhofer Institut für Materialfluss and Logistik.

Li, Y., H. Chen, and C. Prins (2016). Adaptive large neighborhood search for the pickup and delivery problem with time windows, profits, and reserved requests. European Journal of Operational Research 252(1), $27-38$.

Li, Y., A. Lim, W.-C. Oon, H. Qin, and D. Tu (2011). The tree representation for the pickup and delivery traveling salesman problem with $\{$ LIFO $\}$ loading. European Journal of Operational Research 212(3), $482-496$.

Limbourg, S., A. Martin, and C. Paquay (2016). Optimal returnable transport items management. World Conference on Transport Research WCTR 2016 Shanghai.

Liu, R., X. Xie, V. Augusto, and C. Rodriguez (2013). Heuristic algorithms for a vehicle routing problem with simultaneous delivery and pickup and time windows in home health care. European Journal of Operational Research 230(3), 475 - 486. 
Mason, A., A. Shaw, and A. Al-Shamma'a (2012). Peer-to-peer inventory management of returnable transport items: A design science approach. Computers in Industry 63(3), 265274.

Masson, R., S. Ropke, F. Lehuédé, and O. Péton (2014). A branch-and-cut-and-price approach for the pickup and delivery problem with shuttle routes. European Journal of Operational Research 236(3), 849 - 862. Vehicle Routing and Distribution Logistics.

Mihi Ramírez, A. (2012). Product return and logistics knowledge: influence on performance of the firm. Transportation Research Part E: Logistics and Transportation Review 48(5), $1137-1151$.

Min, H. (1989). The multiple vehicle routing problem with simultaneous delivery and pick-up points. Transportation Research Part A: General 23(5), 377-386.

Montané, F. A. T. and R. D. Galvão (2006). A tabu search algorithm for the vehicle routing problem with simultaneous pick-up and delivery service. Computers 6 Operations Research $33(3), 595-619$.

Nagy, G. and S. Salhi (2005). Heuristic algorithms for single and multiple depot vehicle routing problems with pickups and deliveries. European journal of operational research 162(1), 126141.

Nananukul, N. (2013). Clustering model and algorithm for production inventory and distribution problem. Applied Mathematical Modelling 37(24), 9846-9857.

New Zealand Business Council for Sustainable Development (2003). Business guide to a sustainable supply chain - a practical guide. http://www.sbc.org.nz/supplychain/ SupplyChain.pdf.

Pang, K.-W., Z. Xu, and C.-L. Li (2011). Ship routing problem with berthing time clash avoidance constraints. International Journal of Production Economics 131(2), 752 - 762.

Parragh, S. N., K. Doerner, and R. F. Hartl (2008). A survey on pickup and delivery models part I: Transportation between customers and depot. Journal für Betriebswirtschaft 58, $21-51$. 
Pelikán, J. and J. Fábry (2012). Heuristics for routes generation in pickup and delivery problem. Central European Journal of Operations Research 20(3), 463-472.

Petersen, H. L. and S. Ropke (2011). Computational Logistics: Second International Conference, ICCL 2011, Hamburg, Germany, September 19-22, 2011. Proceedings, Chapter The Pickup and Delivery Problem with Cross-Docking Opportunity, pp. 101-113. Berlin, Heidelberg: Springer Berlin Heidelberg.

Pollaris, H., K. Braekers, A. Caris, G. K. Janssens, and S. Limbourg (2014). Capacitated vehicle routing problem with sequence-based pallet loading and axle weight constraints. EURO Journal on Transportation and Logistics, 1-25.

Psaraftis, H. N. (2011). A multi-commodity, capacitated pickup and delivery problem: The single and two-vehicle cases. European Journal of Operational Research 215(3), 572 - 580.

Qu, Y. and J. F. Bard (2013). The heterogeneous pickup and delivery problem with configurable vehicle capacity. Transportation Research Part C: Emerging Technologies 32, 1 20.

Rais, A., F. Alvelos, and M. Carvalho (2014). New mixed integer-programming model for the pickup-and-delivery problem with transshipment. European Journal of Operational Research 235(3), $530-539$.

Ríos-Mercado, R. Z., J. F. López-Pérez, and A. Castrillón-Escobar (2013). Computational Logistics: 4th International Conference, ICCL 2013, Copenhagen, Denmark, September 2527, 2013. Proceedings, Chapter A GRASP for a Multi-depot Multi-commodity Pickup and Delivery Problem with Time Windows and Heterogeneous Fleet in the Bottled Beverage Industry, pp. 143-157. Berlin, Heidelberg: Springer Berlin Heidelberg.

Rosenau, W. V., D. Twede, M. A. Mazzeo, and S. P. Singh (1996). Returnable/reusable logistical packaging: a capital budgeting investment decision framework. Journal of Business Logistics 17(2), 139-165.

Şahin, M., G. Çavuşlar, T. Öncan, G. Şahin, and D. T. Aksu (2013). An efficient heuristic for the multi-vehicle one-to-one pickup and delivery problem with split loads. Transportation 
Research Part C: Emerging Technologies 27, 169 - 188. Selected papers from the Seventh Triennial Symposium on Transportation Analysis (TRISTAN VII).

Sarkis, J. (2006). Greening the supply chain. Springer.

Sifa, Z., C. Jiandong, L. Xiaomin, and L. Keqiang (2011). Urban pickup and delivery problem considering time-dependent fuzzy velocity. Computers Industrial Engineering 60(4), 821 829.

Souza, G. C. (2013). Closed-loop supply chains: A critical review, and future research*. Decision Sciences 44(1), 7-38.

Subramanian, A., E. Uchoa, A. A. Pessoa, and L. S. Ochi (2011). Branch-and-cut with lazy separation for the vehicle routing problem with simultaneous pickup and delivery. Operations Research Letters 39(5), 338 - 341.

Sustainable Packaging Coalition (2011). Definition of sustainable packaging. http: //sustainablepackaging.org/uploads/Documents/Definition $\% 20$ of $\% 20$ Sustainable $\%$ 20Packaging.pdf

Tarantilis, C. D., A. K. Anagnostopoulou, and P. P. Repoussis (2013). Adaptive path relinking for vehicle routing and scheduling problems with product returns. Transportation Science 47(3), 356-379.

Ting, C.-K. and X.-L. Liao (2013). The selective pickup and delivery problem: Formulation and a memetic algorithm. International Journal of Production Economics 141(1), 199 211. Meta-heuristics for manufacturing scheduling and logistics problems.

Toth, P. and D. Vigo (2001). The vehicle routing problem. Society for Industrial and Applied Mathematics.

Van Anholt, R. G., L. C. Coelho, G. Laporte, and I. F. Vis (2013). An inventory-routing problem with pickups and deliveries arising in the replenishment of automated teller machines.

Venkateshan, P. and K. Mathur (2011). An efficient column-generation-based algorithm for solving a pickup-and-delivery problem. Computers Operations Research 38(12), 1647 1655 . 
Wang, H.-F. and Y.-Y. Chen (2013). A coevolutionary algorithm for the flexible delivery and pickup problem with time windows. International Journal of Production Economics 141(1), 4 - 13. Meta-heuristics for manufacturing scheduling and logistics problems.

Zerhouni, H., J.-P. Gayon, and Y. Frein (2013). Influence of dependency between demands and returns in a reverse logistics system. International Journal of Production Economics 143(1), $62-71$. 